case can be explained. The very exaggerated rasping thrill and extremely loud diastolic murmur were caused by the "sonorous vibrations of fluid veins" starting from the fenestrum in the valve, which being situated in the extreme posterior extremity of the right posterior segment, were conducted downwards and backwards, and not downwards and forwards-i.e., along the sternum.

The absence of the double murmur and double pulse in the right femoral, which were present in all the other large arteries, may be accounted for by the pressure exercised upon the external iliac.

I am, Sir, your obedient servant,

David Drummond, M.A., M.D.,

October 27th, 1879. Physician to the Infirmary, Newcastle-on-Tyne.

\section{AMPUTATION AT THE ANKLE-JOINT.}

\section{To the Editor of THE LANCET.}

SIR,-I beg to trouble you with a few remarks on a modification of Syme's amputation at the ankle-joint, which has suggested itself to me, partly because of a case at present under treatment in which about half of the heelflap has sloughed, and also because of the fact that such an accident is of frequent occurrence, more especially in cases of injury. The slow and often unsatisfactory recovery by granulation, and occasionally the necessity of a secondary operation, appear to me to render the following suggestion, if it has not been thought of before, quite a justifiable one. I would propose that in addition to the usual method, a flap be also taken from the front of the foot. This, if no sloughing takes place, will of course prove a redundancy, and will require to be shortened in a few days, but if half or more of the flap dies, and a very few days will decide this, then you have a reserve covering for the bone. This procedure will no doubt prevent the stitching up of the wound at the time of operation, and primarily may appear to be clumsy and unsurgical, but if in a few cases it obviates the necessity of any secondary operation, and in a considerable number of cases shortens the recovery and makes the result more satisfactory, then I think it worthy of trial, if its pros are not ontweighed by its cons, and this I leave for discussion.

I am, Sir, your most obedient servant, Alex. Maxwell AdaMs, F.R.C.S. Edin. Lanark, N.B., October 25th, 1879 .

\section{FOREIGN BODY IN THE BRONCHUS.}

To the Ealitor of THE LANCET.

SIR,-Having read with much interest the case recorded by Dr. Young in your issue of Oct. 18th, headed "Foreign Body in the Right Bronchus, which was expelled on the 102nd day," I beg to forward a sketch of a piece of wood ("teak") which was expelled from the right bronchus upon the bursting of an abscess, after retention for fifteen months. It occurred in the case of my own son. While on his passage to India, he had placed the bit of wood in his mouth, when it suddenly slipped through the windpipe and lodged in the right bronchus.

I remain, Sir, your obedient servant SPENCER T. SMYTH, M.D., F.R.C.S. Eng.

Tyson-road, Forest-hill, Oct. 20th, 1879.

\section{"LOOKING AT HOME."}

To the Editor of THE LANCET.

SIR,-A letter with the above heading was published in The Times on September 27th, calling attention to the defective condition of hotels and lodging-houses in this country as to their sanitary arrangements, and suggesting that a certificate of health, signed by the proper authorities, should be placed in the halls of such places for inspection by visitors.

Your article of October 25th again brings this subject to the notice of the profession and the public, and I venture to think, if continued in your influential journal, will be of great service to all.

In this town, Ramsgate, a move has been made in the right direction. In January of this year the Board of Im. provement Commissioners issued a notice to the ratepayers in these words:- "In the interests of the town, and espe. cially of hotel and lodging-house keepers, the Improvement Commissioners have instructed their proper officers to keep a register of, and grant certificates gratis to, houses duly certified by them to be in a proper sanitary condition."

The certificate is signed by the medical officer of health and town surveyor, after a close examination of the premises, and therefore is a valuable document to the possessor, as will be found out by those who, as you say, " take our money and for our lives they do not care."

I am, Sir, yours obediently,

Ramsgate, Oct. 28th, 1879.

F.R.C.S。

\section{THE WATER-SUPPLY OF SHEFFIELD. \\ To the Editor of THE LANCET.}

SIR,-The paragraph in THE LANCET last Saturday on the above subject was written under a misapprehension of the facts of the case. It is implied in that paragraph that the question at issue is between the Sheffield sanitary authority and their medical officer of health, and that the sanitary authority is in the wrong. This is totally erroneous. The water-supply of this town is in the hands of a private company, and unfortunately the sanitary authority has no control whatever over this company. The Water. works Company have recently sold the ground surrounding some of their reservoirs, and it is now being rapidly built over, roads are being formed, sewers, gas-mains, \&c., will soon follow. I have condemned this proceeding in reports to the sanitary authority, and my opinions have on all points been unanimously adopted. The Health Committee of the Council, without a dissentient voice, approved of my report, and the Town Council unanimously adopted the pro. ceedings of the committee. A memorial has been sent to the Local Government Board asking it to assist the sanitary authority. The difficulties of the case are considerable on all sides, but it is only fair that it should be understood that so far the Town Council of Sheffield has done its duty to the town thoroughly, and has supported its medical officer of health with rare unanimity. Hoping you will in fairness insert this letter

I remain, Sir, yours, \&c,

THE MEDICAL OfFICER OF HeALTH.

Health Office, Sheffield, Oct. 25th.

\section{GLASGOW.}

(From our oun Correspondent.)

THE medical session at Glasgow University was opened on the 28th by the newly-appointed professor of botany, Dr. Balfour, who took for his theme the unity between the animal and plant kingdom; and in conclusion adverted to the question of medical reform from the Scotch University point of view. Dr. Balfour's address was well delivered, and well received by a numerous audience.

At Anderson's College, on the same day, Dr. Andrew Buchanan, President of the Faculty of Physicians and Surgeons, by the request of the medical faculty, gave the opening address. The aged lecturer, in a speech replete with the fire of youth, tempered with the wisdom of eighty years' experience of life, drew a vivid picture of "The Biology of the Present Age," making special reference to milk as a medium of fever, and the question of alcohol as a life-preserver or life-destroyer. Old Glasgow men will be glad to know that, though the hand trembled somewhat, the voice had no faltering tone; and many former students averred that in his green old age Andrew Buchanan was renewing his youth. A perfect ovation awaited him at the conclusion of the address, the audience rising and cheering again and again.

Her Royal Highness the Duchess of CoyNAUGHT, having become a patroness of the Samaritan Free Hospital for Women and Children, has evinced her interest by sending a donation of $£ 25$ in aid of the funds. 